\title{
Investigating the Impact of Cloud Computing Vendor on the Adoption of Cloud Computing
}

\author{
Ge Zhang (iD, Lu Liu, and Hao Guo \\ School of Management Science and Engineering, Shandong University of Finance and Economics, Jinan 250014, China \\ Correspondence should be addressed to Ge Zhang; zhangge0606@163.com
}

Received 17 June 2021; Revised 4 November 2021; Accepted 4 December 2021; Published 26 December 2021

Academic Editor: Ramon Aguero

Copyright (C) 2021 Ge Zhang et al. This is an open access article distributed under the Creative Commons Attribution License, which permits unrestricted use, distribution, and reproduction in any medium, provided the original work is properly cited.

Cloud computing offers significant impacts on organization by changing how information systems are developed, deployed, operated, maintained, and paid for. Therefore, the adoption of cloud computing becomes the focus of relevant research; however, previous studies have mostly studied the factors affecting cloud computing adoption from the perspective of adopters, ignoring the influence of the vendors. This study defines cloud service capability and develops scale to measure it from the perspective of cloud computing vendors to empirically examine the impact of the supply-side of cloud computing. The initial scale of cloud service capability is constructed using qualitative research, and the formal scale is obtained after two rounds of pretest. The statistical results of matched data collected from 132 cloud computing vendors and their users show that cloud service capability significantly affects cloud computing adoption. This study shifts the research perspective on cloud adoption to make theoretical contributions and management insights from the perspective of cloud computing vendors.

\section{Introduction}

Cloud computing is an outcome of combined technologies such as the Internet, distributed systems, virtualization, and multicore chips [1], which allows its users to access the information technology infrastructure and applications on demand through the Internet [2]. Compared to locally deployed information technology applications and solutions, cloud computing is characterized by virtualization, dynamic and high scalability, on-demand deployment, and high flexibility [3-5]. These characteristics have significantly changed the way information systems are utilized. For example, cloud computing reduces the difficulty of acquiring software, allowing companies to obtain more software and stronger computing power at a lower cost [6]; furthermore, cloud computing can be combined with digital technologies such as big data, the Internet of Things (IoT), and artificial intelligence to enhance the scope and depth of application of these technologies [7].

As a result, the cloud computing market is growing rapidly, and increasing traditional IT business starts to offer cloud computing such as Microsoft Azure and Amazon Web
Services. According to the factor and facts' latest report, the global Cloud Computing Market in 2019 was approximately USD 321 Billion and was expected to grow at a CAGR of $18 \%$ and is anticipated to reach around USD 1025.9 Billion by 2026 (https://www.globenewswire.com/news-release/2021/ 01/22/2162789/0/en/Global-Cloud-Computing-Market-

Size-Share-Will-Reach-USD-1025-9-Billion-by-2026-FactsFactors.html). These reports showed that, during the delivery of cloud computing, services play an important role in cloud computing delivery because of its unique characteristics [8]. However, some reports and studies [9] indicate that the level of service in the cloud computing supply industry does not meet the needs of enterprises which intend to migrate their information systems to cloud, decreasing the adoption of cloud computing. The successful implementation of cloud computing necessitates the collaboration of users and vendors [10]. With an increasing number of generic cloud products, the service quality of cloud computing vendors is critical for users to select the right product and implement it effectively [11]. Cloud computing vendors must provide various services in addition to hardware and software, owing to its technical characteristics and 
provisioning model [12], such as fully understanding the customer's business and customizing the development process accordingly [13]. At the same time, emerging technologies such as artificial intelligence and the IoT which are deployed on cloud usually have had a greater impact on business models and processes when applied within enterprises, making enterprises have more customized needs for cloud computing [14] and thus requiring cloud computing venders to provide better quality services.

However, the cloud computing vendors' impact on the adoption of cloud computing has not drawn the attention of scholars. Extant studies mainly analyse the factors which influence cloud computing adoption from the perspective of adopters (e.g., [15]), which does not mean that such impact from vendors is not important [16]. On the contrary, the cloud computing vendors influence the adoption of cloud in many diverse ways. For example, some studies have examined the impact of vendors in terms of perceived reputation and trustworthiness among cloud computing users. The reputation of the vendor is found to affect the adoption of cloud computing [17] and the quality of implementation [18]. According to the signalling theory, the reputation and credibility of the provider are a signal of the quality of the service [19], which means that the quality of vendors' service has an important impact on the adoption and implementation of cloud computing [20]. Service quality which is a trait of the vendor has been proved to be a critical factor of the cloud computing adoption [21]. Therefore, there have been calls for more research on service capability of cloud computing vendors (e.g., [22-24]).

Therefore, this research propounds the research question of how the cloud computing vendors impact the adoption of cloud computing. This study developed the construct of cloud service capability and its scale by qualitative research. Cloud computing vendors and adopters were interviewed using a semistructured approach, and the data were analysed under the guideline of grounded theory. After open coding, axial coding, and forming data structure, the initial questionnaire was obtained. Then pilot test was conducted to adjust the initial questionnaire. Finally, the formal scale was got and used to empirically test cloud service capability's impact on the adoption of cloud computing.

The main contribution of this paper is that it shifts the research perspective from the adopter to the vendor, while most previous researches focused on the adopter's perspective and the cloud computing features perceived by the adopters (e.g., $[15,25])$. Specifically, this study defines cloud service capability, which means the vendor's ability to meet the needs of enterprises migrating to cloud, and develops the scale to measure it and then empirically tests the relationship between the capability and cloud computing adoption. It mainly contributes to constructing the concept of cloud service capability and developing the scale, changing the study of cloud computing adoption from the user's perspective to that of the vendor, and discovering new factors that affect cloud computing adoption. The new factors extended existing technology acceptance models and frameworks and deepened the understanding on cloud computing as service rather than products.
The rest of this paper is organized as follows: We first review the relevant literature in Section 2. Then we present the detailed research design and data collection process in Section 3. The results are presented in Section 4 and the discussion is in Section 5. Section 6 concludes the paper with the discussion of the study's implications, limitations, and future research directions.

\section{Literature Review}

Cloud computing has emerged as a result of the development of parallel computing, distributed computing, and grid computing, as well as the combination of technologies such as the Internet, distributed systems, virtualization, and multicore chips [1]. Its users can use the Internet to access information technology infrastructure and applications ondemand [2]. Cloud computing is classified as Infrastructure as a Service (IaaS), Platform as a Service (PaaS), or Software as a Service (SaaS) depending on how it is used by end-users [2]. It also can be classified as public, private, or hybrid clouds depending on the deployment method [26]. It is distinguished from locally deployed information technology solutions by virtualization, dynamic scalability, on-demand deployment, high expansibility, and high flexibility [5].

Organizations that adopt cloud computing can benefit from it in a variety of ways owing to its technical advantages. First, cloud computing shares hardware and software resources, allowing users to access and use a pool of IT services through the network on a pay-as-you-go basis rather than investing in inhouse computing resources, which can help reduce costs by avoiding the huge expenses incurred in building an in-house IT infrastructure [27, 28]. Especially for small- and medium-sized enterprises, which usually cannot afford the heavy investment in IT infrastructure, cloud computing can significantly reduce the upfront investment and operating costs of IT services [4, 29]. Second, cloud computing outsources IT operations and maintenance to the vendors, allowing enterprises to focus on their core business processes [30]. Third, the scalability [31] and agility [32] of cloud computing enable adopters to rapidly scale their IT infrastructure to respond to customer needs quickly and become more agile and efficient in business operations [33]. Finally, cloud computing allows members of an organization to work in a more flexible environment and facilitates collaboration [34].

Despite many positive impacts for businesses, cloud computing adoption still encounters significant resistance $[35,36]$, making cloud computing adoption one of the hotspots of relevant research $[37,38]$. According to the review of Zhang, Chen, and Li [39], the number of researches on cloud computing adoption is increasing year by year, from 14 in 2011 to 167 in 2019. Academics generally study cloud computing adoption from two perspectives: factors that promote adoption and factors that hinder it. The main factors that can facilitate the adoption of cloud computing in an organization are top management support [40], compatibility [41], the level of informatization of the organization, and the competition faced by the organization pressure [42], while factors that hinder the adoption of cloud computing by enterprises are mainly security and privacy of cloud computing $[43,44]$, the lack of legitimacy 
[45], and the overall social environment, such as poor IT infrastructure in developing countries [46]. The main theories used in related studies include the Technology-OrganizationEnvironment (TOE) framework [47], the Technology Acceptance Model (TAM) [48, 49], and migration theory [50]. Scholars have also integrated these theories to better explain the adoption of cloud computing, for example, by integrating TOE with TAM [51] and Diffusion of Innovation (DOI) Model with TOE [52].

A review of the literature shows that studies on cloud adoption have focused on users of cloud computing, neglecting one key role, the vendors. Although the $\mathrm{E}$ of the TOE model refers to environmental factors, it mainly addresses the macroeconomic policy and competitive environment in which the firm is located [53], and the object of the study is still firms migrating to cloud [54]. Thus, the extant studies lack exploration from the perspective of the supply side of cloud computing. However, supply-side factors also have an important impact on the selection and implementation of cloud services by enterprises [55]. Therefore, attention should be given to the capabilities of the supply-side [3].

Although software is still the carrier of cloud computing [56], its technical characteristics and provisioning model lead to strong service characteristics [57]; that is, in addition to the hardware and software products deployed on cloud, it also provides many supporting functions [12], which exerts higher demands on the service capabilities of cloud computing vendors. Because cloud computing enables highly elastic and scalable service configurations [58], vendors must be able to deliver additional resources and services to meet users' changing or even extremely diverse needs. In terms of usage, because cloud computing users access computing resources, software, and hardware services remotely over the Internet [10], cloud computing vendors must better understand the needs of their users. Cloud computing vendors must be able to build a service portfolio to meet customer needs, because the task is frequently accomplished by combining different resources [59]. Because cloud computing uses a "pay-as-you-go" billing model, in which users only pay for the time they are subscribed [60], cloud computing vendors must be able to offer services at a lower cost. Users storing data in the cloud may be concerned about security and privacy breaches [61], so the vendors must understand how to safeguard customer data security and privacy. In terms of externalities, the more cloud users in the supply chain, the greater the revenue generated per user [62]; therefore, cloud computing vendors should have the ability to assist customers in promoting cloud computing usage. Through the literature review, it can be found that the current situation necessitates research from the perspective of cloud computing vendors rather than just technical capabilities and offers new avenues for research on the adoption of cloud computing.

\section{Methods and Data}

3.1. Development of the Scale of Cloud Service Capability. In order to explore how the supply-side of cloud computing influences its adoption, this study defines the cloud service capability of cloud computing vendor which means the vendor's ability to meet the needs of enterprises migrating to cloud, develop the scale to measure it, and empirically test its impact on the adoption of cloud computing. The development process of the scale is shown in Figure 1.

Cloud service capability is a novel construct without preexisting scale to measure it; therefore, the first task of this study is to develop a scale for it. Following the guidelines provided by MacKenzie, Podsakoff, and Podsakoff [63], 8 cloud computing vendors and 16 customers of these vendors (two from each vendor) were interviewed in the field. Then the qualitative data were analysed under the guideline of grounded theory to obtain the questionnaire. The work followed the steps of open coding, axial coding, forming data structure, and constructing initial questionnaires.

3.1.1. Open Coding. Open coding is to extract themes that represent the data by analysing the raw data [64]. This study takes a quote from the cloud computing vendor (S01) as an example to illustrate the operation of open coding. The manager in charge of S01 described their business:

"We mainly provide SaaS, such as smart industrial parks and integrated e-commerce. We cooperate with Huawei and Inspur, for example, our platform offers Huawei voice services and financial software developed by Inspur. However, during the process of implement of cloud computing, we found that the requirements of every customer were different. We have to provide customized services to satisfy them. We developed a cloud platform for the entire industry chain. However, in fact, the demand is different for every customer. Because in information technology industry, there may be very few standard requirements, except for a few simple requirements. This requires us to create what each enterprise needs, so we focus on the implement of cloud computing, and we adjusted the development process to meet the various requirements of the customers. For example, some enterprises require industrial Internet. We predict customer needs by summing up experience and modify former-developed systems to meet the new requirements. We offer the traceability system of the entire industrial chain according the features of the customers business scope."

The data were analysed verbatim to summarize the meaning expressed by the interviewee in each sentence. The meaning was then expressed in concise language to obtain themes list as follows:

(1) Providing SaaS;

(2) Mainly providing platform services and information technology services to customers;

(3) The requirements of each enterprise are different;

(4) Huawei, Inspur;

(5) Providing customized services;

(6) Predicting customer needs;

(7) There are very few standard requirements models;

(8) Each adopter has different requirements;

(9) Adjusting the development process for the adopters; 


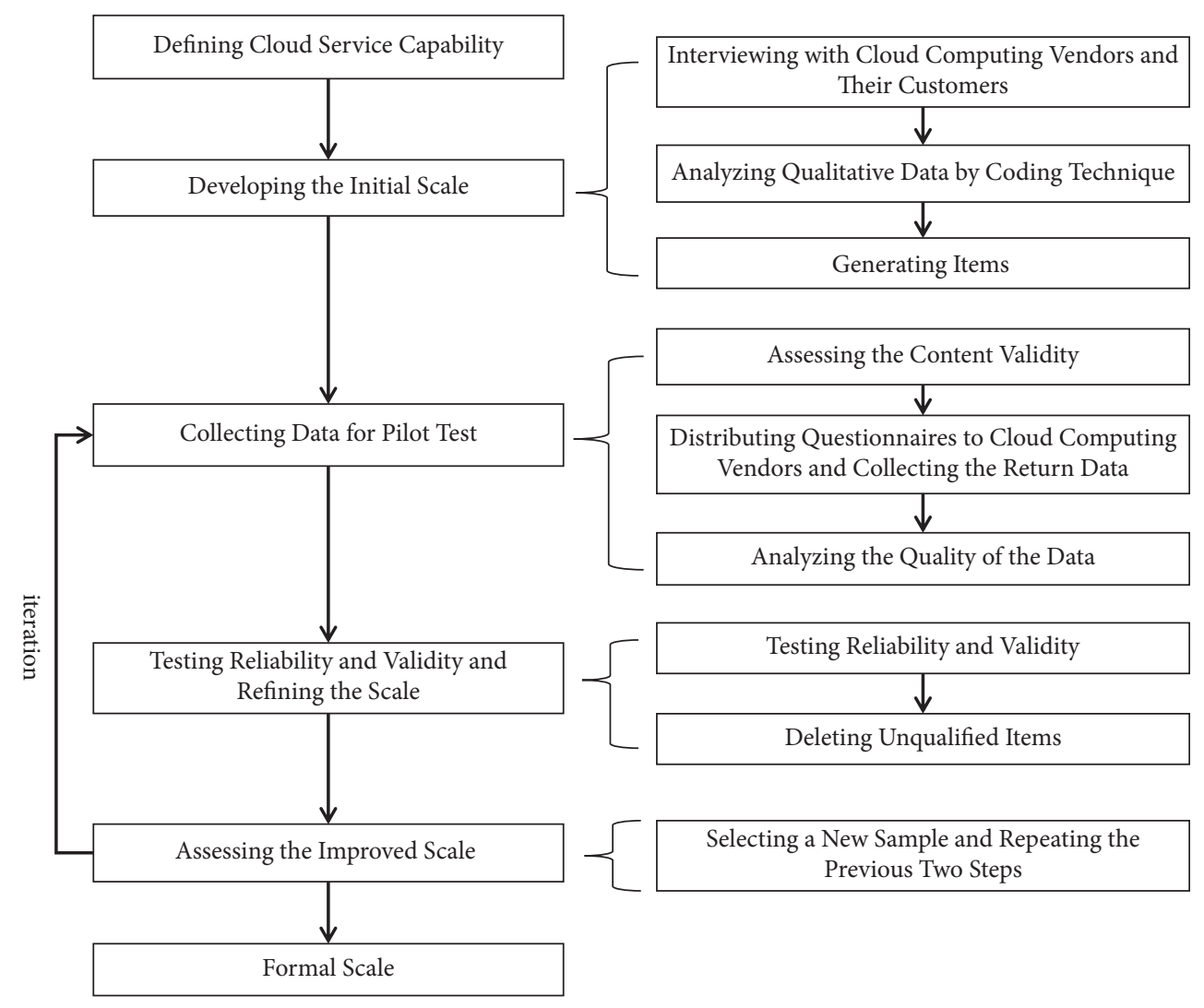

Note: iteration ends till the data meet the statistical criteria

FIgURE 1: The technical roadmap of cloud service capability scale development.

(10) Creating an industrial chain;

(11) Redevelopment of former systems to meet the new requirements;

(12) Industrial Internet;

(13) Traceability system for the entire industry chain.

Themes (1) and (2) show the types of products and services provided by S01, and themes (3), (7), and (8) show the requirements of enterprises. Themes (5), (6), (9), and (10) show the services that S01 provides to meet the customized requirements of companies, which include summarizing past service experiences, anticipating customer needs, and adjusting the development process in the implementation of cloud computing. Themes (4), (11), (12), and (13) show that S01 integrated industry resources including hardware infrastructure providers, such as Huawei, and software providers, such as Inspur, to better serve the adopters.

This study conducted open coding to analyse all the data collected by interview and a total of 895 themes were obtained.

3.1.2. Axial Coding. Axial coding is the process that categorizes the themes obtained by open coding to get subjects [65]. Table 1 is an example of the axial coding of technical capability.
The internal consistency validity of the axial coding should be measured. This study followed the principles offered by Cicchetti [66] and MacKenzie et al. [63] to examine internal consistency validity. After calculation, evaluation, and adjustment, the cross-discrimination reliability all achieved an excellent level of 0.9 or higher, which demonstrates that the results of axial coding were acceptable.

3.1.3. Forming Data Structures. This step uses the aggregate coding to form the data structure to obtain the dimensions of cloud service capabilities and the questionnaire. In this study, since open coding and axial coding had been conducted, aggregating the results of coding can form data structure. Table 2 is an example of the aggregate coding of technical capability.

Data structure, on the one hand, forms an overall description for the data and, on the other hand, shows how this study develops the data into construct and its dimensions. It demonstrates the content and structure of the construct comprehensively to present persuasive evidence and show the chain from data to construct. Therefore, the data structure can be used to form a preliminary questionnaire.

3.1.4. Constructing Initial Questionnaires. After forming data structure, the initial questionnaire was obtained, where the results of aggregate coding were used as dimensions of 
TABLE 1: Example of the axial coding of technical capability.

\begin{tabular}{|c|c|}
\hline Axial coding (subjectives) & Open coding (themes) \\
\hline $\begin{array}{l}\text { We are very capable of developing } \\
\text { cloud computing }\end{array}$ & $\begin{array}{l}\text { (1) We rank the first in the province for storage; (2) we are the leading cloud server in China; }(3) \\
\text { each technician should know } 2 \text { or more programming languages; (4) our product is better than } \\
\text { the peers. }\end{array}$ \\
\hline $\begin{array}{l}\text { We are constantly updating our } \\
\text { technology }\end{array}$ & $\begin{array}{l}\text { (1) We train our employees to keep them updated with the latest technology; (2) we offer private } \\
\text { cloud, public cloud, and now multicloud; (3) the architecture of our products has been updated } \\
\text { for several generations. }\end{array}$ \\
\hline Our products are highly scalable & $\begin{array}{l}\text { (1) We examine the original system of the enterprise and try to achieve data sharing; (2) our } \\
\text { products are very easy to expand; (3) all products are developed in a modular approach; (4) new } \\
\text { modules can be added at any time. }\end{array}$ \\
\hline $\begin{array}{l}\text { Our products have very high } \\
\text { performance }\end{array}$ & $\begin{array}{l}\text { (1) The failure warning system deployed on our servers has an accuracy rate of more than } 98 \% ;(2) \\
\text { compared to the customer's own storage room, ours is massive. }\end{array}$ \\
\hline Our products are highly flexible & $\begin{array}{c}\text { (1) We can always change our service according to the customer's requirement; (2) there are } \\
\text { many standard modules of our product, which can be changed according to the business } \\
\text { processes. }\end{array}$ \\
\hline
\end{tabular}

TABLE 2: Example of the aggregate coding of technical capability.

\begin{tabular}{|c|c|c|}
\hline $\begin{array}{l}\text { Aggregate coding } \\
\text { (dimensions) }\end{array}$ & Axial coding (subjectives) & Open coding (themes) \\
\hline \multirow{5}{*}{ Technical capability } & $\begin{array}{l}\text { We are very capable of } \\
\text { developing cloud computing }\end{array}$ & $\begin{array}{l}\text { (1) We rank the first in the province for storage; (2) we are the leading cloud } \\
\text { server in China; (3) each technician should know } 2 \text { or more programming } \\
\text { languages; (4) our product is better than the peers. }\end{array}$ \\
\hline & $\begin{array}{l}\text { We are constantly updating our } \\
\text { technology }\end{array}$ & $\begin{array}{l}\text { (1) We train our employees to keep them updated with the latest technology; } \\
\text { (2) we offer private cloud, public cloud, and now multicloud; (3) the } \\
\text { architecture of our products has been updated for several generations. } \\
\text { (1) We examine the original system of the enterprise and try to achieve data }\end{array}$ \\
\hline & Our products are highly scalable & $\begin{array}{l}\text { sharing; (2) our products are very easy to expand; (3) all products are } \\
\text { developed in a modular approach; (4) new modules can be added at any time. }\end{array}$ \\
\hline & $\begin{array}{l}\text { Our products have very high } \\
\text { performance }\end{array}$ & $\begin{array}{c}\text { (1) The failure warning system deployed on our servers has an accuracy rate of } \\
\text { more than } 98 \% \text {; (2) compared to the customer's own storage room, ours is } \\
\text { massive. }\end{array}$ \\
\hline & Our products are highly flexible & $\begin{array}{l}\text { (1) We can always change our service according to the customer's } \\
\text { requirement; (2) there are many standard modules of our product, which can } \\
\text { be changed according to the business processes. }\end{array}$ \\
\hline
\end{tabular}

the construct, and the subjects of axial coding were used as items of the questionnaire. Then, the pilot test was conducted to examine the reliability and validity of the scale.

In order to examine the reliability and validity of the scale, a pretest was conducted in the form of questionnaires. The items of the initial scale were measured by 7-point Likert scales. The test subjects scored the items according to their actual situation, where 1 to 7 indicated their level of agreement with the situation described in the question items, with 1 indicating strongly disagree and 7 indicating strongly agree. Before distributing the questionnaire to collect data, two experts in the field of cloud computing were invited to verify the questionnaire and provide feedback on the instructions, the items (including its wording), and the structure of the questionnaire. After reading the questionnaire and filling it out, they indicated that no major changes were necessary except for some minor issues in wording. They also confirmed that the whole questionnaire was clearly presented and was easy to understand.

The questionnaires were distributed to the second (2018) and third (2019) batches of excellent vendors of cloud computing which were approbated by the Department of Industry and Information Technology of Shandong Province and Jinan
City Bureau of Industry and Information Technology. 144 vendors were recommended by the Provincial Department of Industry and Information Technology, and 118 vendors were recommended by the municipal Bureau of Industry and Information Technology. After removing the duplicate vendors from the 2 recommended lists, a total of 182 cloud computing vendors were obtained. The questionnaires were distributed through "Public Service Platform for Promoting Enterprises in Shandong Province to Migrate to Cloud," a website through which the Shandong Province evaluated the status of enterprises migrating to cloud. The questionnaire was uploaded to this platform, and a notification was sent to the sample enterprises. Then, the head of the enterprise or the head of the business department logged in to the website and filled out the questionnaire. A total of 142 questionnaires were collected.

After the questionnaires were collected, their quality was examined. The questionnaires with all questions were scored the same, and those that took less than three minutes to complete were excluded. This exclusion is based on the fact that if a questionnaire filler fills in more than 15 question items in 1 minute, there is a high probability that he did not fill in the questionnaire carefully or even chose randomly to complete it [67]. The final number of usable questionnaires was 121 . 
The recovered data were then statistically analysed to verify the reliability and validity of the scale. Reliability analysis was tested using Cronbach's alpha and the Corrected Item-Total Correlation (CITC). According to the results of the data analysis, the alpha values for each dimension of the initial scale were $>0.7$, which met the statistical criteria, and no question items had CITC values less than 0.4 ; thus, there was no need to remove the items.

Next, KMO and Bartlett's tests were conducted to verify whether the data is suitable for factor analysis. The data analysis resulted in a KMO value of 0.939 , which is greater than the critical value of 0.9. The significance level of Bartlett's test was 0.000 , which met the significance level of the 0.05 criterion, which indicated that the scale was suitable for factor analysis.

Subsequently, the data were subjected to principal component analysis. From the results of the data analysis, the first component eigenvalue is 14.641, and the variance contribution is $19.13 \%$, while the second component eigenvalue is 3.336 , and the variance contribution is $15.65 \%$. It is from the eighth principal component that the eigenvalue starts to be less than 1. According to one of the conditions of factor analysis, the eigenvalue is greater than 1; thus, the sample data can be extracted into seven principal components. The cumulative contribution of these components reaches $84.29 \%$, which covers most of the information of cloud service capability; therefore, the scale has good validity.

Finally, the data were collected to conduct exploratory factor analysis. The results revealed that most of the question items were clustered under each of the constructs of cloud service capability, but question items 15, 18, and 19 had strong loadings on both component 3 and component 5 (meaning that the difference in loadings on the two components was only less than 0.4), and question item 12 had strong loadings on both component 2 and component 4 . Thus, according to the rules of factor analysis, question items $12,15,18$, and 19 were deleted along with question item 9, which did not have strong loadings on all seven main components (all less than 0.5). Question item 3 had a greater loading on component 7 than on component 1 , and question item 36 had a greater loading on component 5 than on component 6; therefore, the construct reflected by the question item needed to be adjusted. Ultimately, question items $12,15,18$, and 19 were deleted while adjusting for the constructs reflected in question items 3 and 36.

After the scale was pretested for refinement, it is necessary to select new sample to retest the refined scale [63]. The same method was chosen for this retest as for the previous pretest, following the same criteria for distributing the questionnaire and collecting data. To avoid sample duplication between the two pretests, a sample pool of cloud computing vendors in Zibo City was selected, and 153 valid questionnaires were collected. Exploratory factor analysis was performed on these questionnaires, and the results of these are shown in Table 3. The data results showed that the loadings of all question items met the statistical criteria, and the average variance extracted (AVE) and composite reliability (CR) values of each dimension were calculated using
AMOS. The AVE of all dimensions was greater than 0.5 , and the CR was greater than 0.7 in all, indicating that the scale had good reliability and convergent validity. The final formal scale for measuring cloud service capability was obtained.

\subsection{Research Model and Hypothesis Development.} According to the conceptualization of the construct of cloud service capability and the development of its scale as this paper discussed above, the cloud service capability can be divided into 7 dimensions which are technical, security, customer domain knowledge, marketing, consulting, platform, and responsiveness. All of them have the positive impact on cloud computing adoption; then we will elaborate the hypotheses by explaining the relationships of them in the rest of this section; the research model is shown in Figure 2.

\subsubsection{The Relationship between Technical Capability and} Cloud Computing Adoption. Technical capability refers to the cloud computing vendors' ability to develop advanced cloud computing products and keep technical advantages of the products. Technical factors are important determinants of the adoption of cloud computing. For example, the complexity of cloud computing is an important factor that influences its adoption, and the more complex cloud computing is, the more reluctant companies are to adopt it. The ease of access and scalability of cloud computing and the stability and powerful storage capacity of it would also enhance the likelihood of user adoption [15, 68]. The technical capability of cloud computing vendors influences the complexity of these products, and providers with strong development capability can develop more concise cloud computing products, such as more adaptable cloud desktop office systems [69], thus enhancing cloud computing adoption. Therefore, we propose the following hypothesis:

H1: Technical capability positively influences the adoption of cloud computing.

3.2.2. The Relationship between Security Capability and Cloud Computing Adoption. Security capability refers to the cloud computing vendors' ability to protect the security and privacy of customer data. Cloud computing requires users to store their data in the cloud, which leads users to lose complete control over their data [70] and raises concerns about data security and privacy issues [71]. The fact that the users' data are stored in the same resource pool in cloud computing might introduce their concerns about data leakage [72]. Thus, security issues become a significant hindrance to the adoption of cloud computing [73, 74]. Some research states that, for SMEs, the lack of capital, technology, and personnel will lead to the low security of information systems, while cloud computing providers will invest more in security and have professionals responsible for system security due to their professionalism [75]. Therefore, security should not be a hindrance for enterprises to adopt cloud computing; instead, adopting cloud computing is the best option for SMEs to achieve higher security 
TABLE 3: Factors analysis of modified cloud service capability.

\begin{tabular}{|c|c|c|c|c|c|}
\hline & Items & Loading & AVE & $\alpha$ & $\mathrm{CR}$ \\
\hline \multirow{5}{*}{ Technical capability (TECC) } & We are very capable of developing cloud computing & 0.587 & \multirow{5}{*}{0.509} & \multirow{5}{*}{0.905} & \multirow{5}{*}{0.900} \\
\hline & We are constantly updating our technology & 0.652 & & & \\
\hline & Our products are highly scalable & 0.730 & & & \\
\hline & Our products have very high performance & 0.791 & & & \\
\hline & Our products are highly flexible & 0.706 & & & \\
\hline \multirow{4}{*}{ Security capability (SECC) } & We do not snoop on our customers' data & 0.813 & \multirow{4}{*}{0.690} & \multirow{4}{*}{0.885} & \multirow{4}{*}{0.792} \\
\hline & We do not steal our customers' data & 0.828 & & & \\
\hline & We invest in security technology & 0.794 & & & \\
\hline & Data security is our main concern & 0.692 & & & \\
\hline \multirow{4}{*}{$\begin{array}{l}\text { Customer domain knowledge } \\
\text { capability (CDKC) }\end{array}$} & We know our clients' industries & 0.607 & \multirow{4}{*}{0.560} & \multirow{4}{*}{0.828} & \multirow{4}{*}{0.792} \\
\hline & We are familiar with the business in which our clients are involved & 0.861 & & & \\
\hline & $\begin{array}{c}\text { We adapt the cloud implementation process to the customer's } \\
\text { requirements }\end{array}$ & 0.705 & & & \\
\hline & We will adapt the cloud architecture to the customer's requirements & 0.894 & & & \\
\hline \multirow{5}{*}{ Marketing capability (MARC) } & Our prices are very advantageous & 0.664 & \multirow{5}{*}{0.569} & \multirow{5}{*}{0.704} & \multirow{5}{*}{0.629} \\
\hline & We offer our customers a discount on ongoing use & 0.626 & & & \\
\hline & We will show our customers the benefits of cloud computing & 0.752 & & & \\
\hline & We show our customers what we have to offer & 0.615 & & & \\
\hline & We offer marketing education campaigns to potential customers & 0.611 & & & \\
\hline \multirow{6}{*}{ Consulting capability (CONC) } & We help CIOs convince CEOs of the importance of cloud computing & 0.739 & \multirow{6}{*}{0.574} & \multirow{6}{*}{0.839} & \multirow{6}{*}{0.691} \\
\hline & We will advise on client management & 0.521 & & & \\
\hline & $\begin{array}{l}\text { We help companies plan and optimize their business processes with } \\
\text { cloud computing }\end{array}$ & 0.717 & & & \\
\hline & $\begin{array}{c}\text { We help companies transform their business models with cloud } \\
\text { computing }\end{array}$ & 0.791 & & & \\
\hline & We help companies leverage the cloud for digital transformation & 0.558 & & & \\
\hline & $\begin{array}{c}\text { We help our clients integrate their upstream and downstream } \\
\text { businesses }\end{array}$ & 0.791 & & & \\
\hline \multirow{6}{*}{ Platform capability (PLAC) } & We do not lock our customers into the cloud services we offer & 0.622 & \multirow{6}{*}{0.552} & \multirow{6}{*}{0.705} & \multirow{6}{*}{0.501} \\
\hline & $\begin{array}{l}\text { There is compatibility between my cloud computing product and other } \\
\text { companies' cloud computing products }\end{array}$ & 0.717 & & & \\
\hline & We offer complete cloud computing solutions & 0.791 & & & \\
\hline & We integrate infrastructure providers & 0.760 & & & \\
\hline & We integrate SaaS providers & 0.791 & & & \\
\hline & We have integrated PaaS providers & 0.807 & & & \\
\hline \multirow{3}{*}{ Responsiveness (RESP) } & Customer cloud services are running very stably & 0.654 & \multirow{3}{*}{0.759} & \multirow{3}{*}{0.901} & \multirow{3}{*}{0.747} \\
\hline & $\begin{array}{c}\text { We can be alerted immediately to problems in the operation of } \\
\text { customer clouds }\end{array}$ & 0.516 & & & \\
\hline & $\begin{array}{c}\text { We can respond immediately to problems in customer cloud } \\
\text { operations }\end{array}$ & 0.685 & & & \\
\hline
\end{tabular}

levels for their information systems [76]. Therefore, we propose the following hypothesis:

$\mathrm{H} 2$ : Security capability positively influences the adoption of cloud computing.

\subsubsection{The Relationship between Customer Domain Knowl-} edge Capability and Cloud Computing Adoption. Customer domain knowledge capability refers to the cloud computing vendors' ability to master the customer's domain knowledge and use it to provide better services to the customer. In software development, customer domain knowledge capability is important [77]; customer expertise enables the developers to better understand customer needs [78], provide customized products or services based on these needs [79], and adapt their own development process to suit customer needs [13], thus increasing the likelihood of product or service adoption. Therefore, in cloud computing, vendors who have more customer domain knowledge can eliminate customers' business concerns [80], improve service quality [81], and offer a better experience, which then also increases the likelihood of cloud adoption [82]. Additionally, for providers, the better the understanding of their customers is, the better the experience they can provide to them, thus enhancing the adoption of cloud computing. Therefore, we propose the following hypothesis:

H3: Customer domain knowledge capability positively influences the adoption of cloud computing.

3.2.4. The Relationship between Marketing Capability and Cloud Computing Adoption. Marketing capability refers to the cloud computing vendors' ability to educate potential customers about cloud computing and promote them to use it. Cloud computing as an emerging technology has low user acceptance and requires market education for users [83] in 


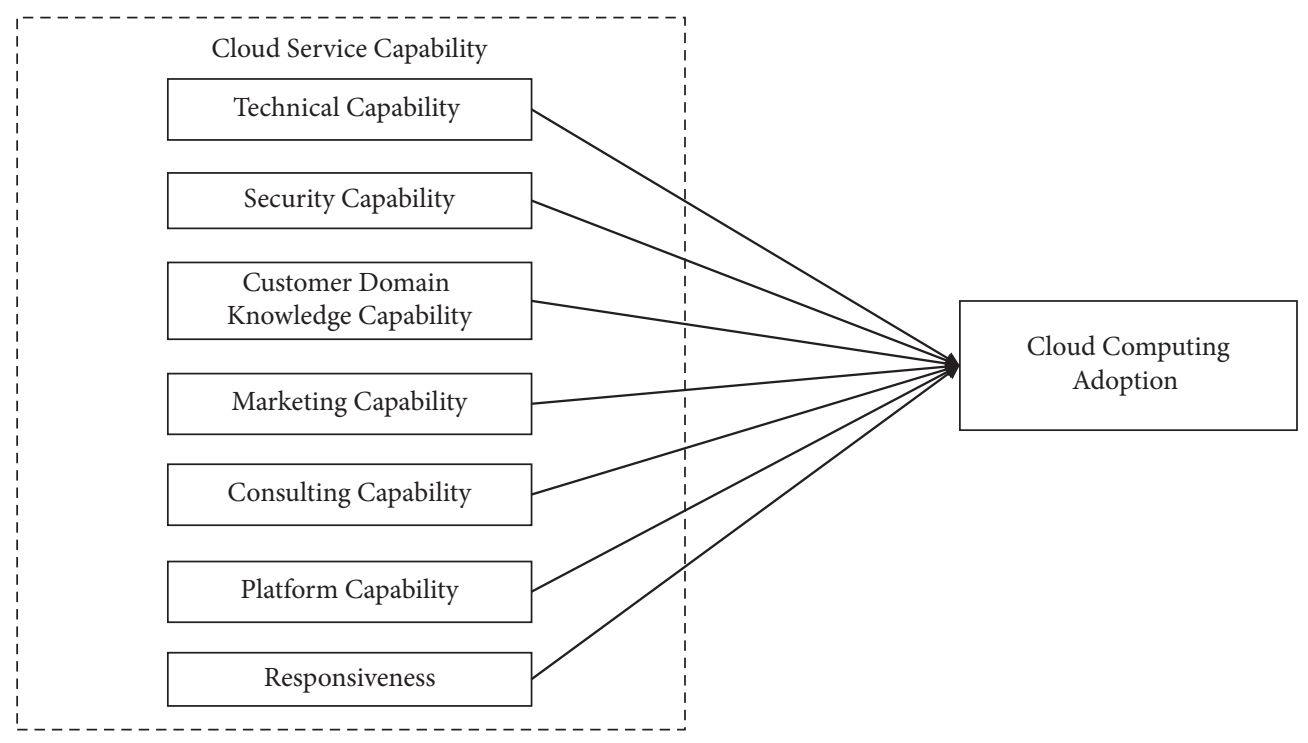

Figure 2: The model of this research.

order to increase their adoption [84]; moreover, marketing plays a vital role in increasing the product awareness among customers and consumers of the product [85]. Cloud computing vendors can also offer discounts when companies continue to subscribe to the service as a promotional tool-a crucial factor for enhancing cloud adoption [86]. Therefore, we propose the following hypothesis:

H4: Marketing capability positively influences the adoption of cloud computing.

\subsubsection{The Relationship between Consulting Capability and} Cloud Computing Adoption. Consulting capability refers to the ability of cloud computing vendors to provide relevant consulting to customers to improve customer management during which they provide cloud products to the customers. Cloud computing vendors can help CIOs of their customers to gain top management support when providing cloud product [87] or provide relevant consulting directly to CEOs to obtain support for cloud implementations [88, 89]. When combined with technologies such as big data and the IoT, cloud computing might transform organizational business models more profoundly than traditional information systems [90] to achieve digital transformation; consulting can help the transformation through imitation [91]. Therefore, cloud computing adoption can be enhanced if cloud vendors can provide relevant consulting to costumers. We propose the following hypothesis:

H5: Consulting capability positively influences the adoption of cloud computing.

\subsubsection{The Relationship between Platform Capability and} Cloud Computing Adoption. Platform capability refers to the ability of a cloud computing vendors to integrate supplyside resources to provide a "packaged" solution to its customers. Cloud computing has positive network externalities [92], and cloud service providers with stronger platform capability can reduce the complexity and increase the compatibility of cloud services [68], as well as reducing uncertainty in cloud service implementation [93], thereby increasing the adoption of these services. Therefore, we propose the following hypothesis:

H6: Platform capability positively influences the adoption of cloud computing.

\subsubsection{The Relationship between Responsiveness and Cloud} Computing Adoption. Responsiveness refers to the ability of cloud computing vendor to find errors and deal with them in a timely manner to ensure that the customer's operations are not significantly affected when the cloud fails. As the use of cloud computing is a continuous behaviour, the vendor's ability to provide continuous support to the user during the process is an important reason to influence its adoption. Previous studies from the user's perspective have attributed the support provided by the vendor to security [46] or perceived ease of use [94]. However, in fact, since the characteristics of cloud computing are more inclined to services, it is no longer appropriate to reuse the support of product characteristics. From another perspective, since cloud services are hosted in the cloud and users do not need specialized technicians, there is a greater need for cloud service providers to be able to react quickly to failures in cloud computing usage [28]. Therefore, we propose the following hypothesis:

H7: Responsiveness positively influences the adoption of cloud computing.

\subsection{Measurement}

Cloud Service Capability. The scale of cloud service capability was developed by ourselves.

The Adoption of Cloud Computing. The scale of adoption of cloud computing was adapted from the scale used by Oliveira, Thomas, and Espadanal [52]. Since the original scale is 
in English, this research adopted back-translation procedures [95] to ensure that the English and Chinese versions of the questionnaire convey the same meaning. First, a Ph.D. student major in information systems was invited to translate the scale into Chinese; then, another Ph.D. student was asked to translate the translated scale back into English, and it was ensured that the two Ph.D. students worked independently of each other. Finally, a bilingual professor of information systems compared the back-translated version with the original English version of the questionnaire to test their consistency.

The data of the adoption of cloud computing was collected from the users of the vendors to form matched data. As there are more than two users matched to each vendor, this study assessed the agreement within the responses from users served by the same vendor via $r_{w g}$ to ensure that we could average across responses [96]. Results showed that the median and mean level of users' agreement for adoption of cloud computing were each above 0.70 (with $93.3 \%$ of responses having an agreement of over 0.70 ), which indicates substantial agreement within the responses from users served by the same vendor. Therefore, the values of adoption of cloud computing were based on the average of the users served by the same vendor.

Control Variables. In this study, the types and sizes of the vendors were selected as control variables. The types and sizes of cloud computing vendors are the signals of the quality of their offers and capability $[18,19]$ and make a significant difference in information security, privacy, and business integrity of their products, which can affect users' feelings on cloud computing and thus their adoption of cloud computing $[97,98]$. The types of cloud vendors can be categorized into IaaS vendors, PaaS vendors, SaaS vendors, and hybrid vendors [2] and they are valued by $0,1,2$, and 3 , respectively. The size is measured by the number of employees in the vendors. The complete questionnaire can be seen in the Appendix.

3.4. Data Collection. This study adopted a match data collection approach to gather data and test the proposed hypotheses, in which questionnaires on cloud service capability were filled out by cloud computing vendors, and those on cloud adoption were filled out by the customers corresponding to the vendors. Each vendor was required to contact at least five customers to fill out the questionnaire. To avoid using the same sample as when developing the cloud service capability scale, the cloud computing vendors in Qingdao and Yantai and other cities in Shandong Province were selected, and they were also asked to contact their customers to fill in the scales on cloud adoption. The scales were marked in our study to ensure the match between the independent and dependent variables in the data analysis. The questionnaire was distributed to 202 vendors, and 163 completed questionnaires were eventually returned. Among the 163 vendors that returned questionnaires, 144 returned with at least five of the customers they served who completed the questionnaire on cloud computing adoption.
After removing questionnaires in which the response time was significantly out of the normal time frame and where the same result was selected for all questions, a total of 132 questionnaires were obtained from vendors and 837 questionnaires from the customers, corresponding to an average of 6.34 customers per vendor.

\section{Data Analysis and Hypothesis Testing}

4.1. Nonresponse Bias Test and Common Method Bias Test. According to the test for nonresponse bias proposed by Armstrong and Overton [99], the sample was divided into two groups according to the order of responses and independent-samples $t$-tests were conducted, which showed no significant difference in the variable scores between the two groups. Thus, this study showed no significant nonresponse bias. This study applied the following methods to test for common method bias. First, according to Harman's singlefactor test [100], all question items of independent variables and dependent variables were subject to principal component analysis, and a total of eight factors were extracted using eigenvalues greater than 1 . The total variance explained by the first factor is $16.472 \%$. Second, in the case of serious common method bias, the correlation coefficient between the constructs would be very high, for example, possibly higher than 0.9 [101], while the highest of the correlation coefficients between the constructs in this study was 0.565 . Therefore, combining the above two methods, serious common method bias did not exist in our study.

4.2. Descriptive Statistical Analysis. Table 4 demonstrates the descriptive statistical analysis results of the sample. It is observed that most of the cloud computing vendors provide hybrid services (58.18\%). One possible reason for the smallest share of cloud service providers in the infrastructure category is the high cost of acquisition, installation, and maintenance of cloud computing and storage equipment. Regarding enterprise size, cloud service providers are all small, with $72.26 \%$ of the providers employing only 1-99 individuals. A possible reason is that the cloud service industry and providers are undergoing a period of development, resulting in the small size of enterprises. In addition, the analysis of the questionnaire reveals that infrastructure providers are large-a situation similar to that of infrastructure providers in other industries, where only few of them are needed to meet a large number of infrastructure needs. This is also consistent with the least share in the infrastructure category of cloud computing services.

4.3. Confirmatory Factor Analysis. In this study, the covariance-based structural equation model (CB-SEM) approach was used to perform confirmatory factor analysis (CFA). CB-SEM has greater advantages over partial least-squares-based structural equation model (PLS-SEM) in terms of the model fit analysis, and the CBSEM models are more suitable for factor-based models $[102,103]$. Therefore, this research chose AMOS to conduct the confirmatory factor analysis on the 
TABLe 4: Descriptive statistical analysis of cloud service providers.

\begin{tabular}{lccc}
\hline Type of service & Percentages (\%) & Business size (persons) & Percentages (\%) \\
\hline IaaS vendors & 5.11 & $1-99$ & 72.26 \\
PaaS vendors & 12.41 & $99-499$ & 18.98 \\
SaaS vendors & 24.31 & $499-1000$ & 7.20 \\
Integrated vendors & 58.17 & $>1000$ & 1.56 \\
\hline
\end{tabular}

questionnaire data, which consisted mainly of the goodness of fit (GoF) analysis, as well as the reliability and validity tests.

In terms of the GoF of the model, this study performed a one-, two-, three-, four-, five-, six-, and seven-factor model fit analysis for cloud service capability (see Table 5). The results indicate that the seven-factor model had the best fit $(\chi 2 / \mathrm{df}=1.713 ; \quad \mathrm{CFI}=0.972 ; \quad \mathrm{TLI}=0.958 ; \quad \mathrm{RMSEA}=0.088 ;$ SRMR $=0.057)$ [104-106]. Therefore, this study used cloud service capability as a seven-factor construct to examine each of these seven dimensions on cloud computing adoption.

Then, we used AMOS to assess the reliability and validity of the scale data. As shown in Table 6, Cronbach's alpha coefficients of all constructs are over 0.7 , suggesting sufficient construct reliability $[107,108]$. The AVE of each construct exceeds 0.5 , and the $\mathrm{CR}$ of each construct is above 0.7 , thus suggesting sufficient convergent validity [109-111].

Table 7 shows the correlation matrix between the variables. The results show that the square root of each construct's AVE is much greater than the construct's correlations with any other construct, suggesting great discriminant validity [112].

4.4. Hypothesis Testing. Finally, SPSS was used to test the hypotheses and obtain the regression coefficients for each hypothesis. Figure 3 presents and visualizes our results.

As shown in Figure 3, the model explains $40.5 \%$ of the variance for cloud computing adoption, suggesting that our research model has good explanatory power. Technical capability $\quad(\beta=0.060, \quad p<0.001)$, security capability $(\beta=0.120, p<0.001)$, customer domain knowledge capability $(\beta=0.293, p<0.001)$, marketing capability $(\beta=0.207$, $p<0.001)$, consulting capability $(\beta=0.390, p<0.001)$, platform capability $(\beta=0.526, p<0.001)$, and responsiveness $(\beta=0.168, p<0.05)$ of cloud computing vendors all have significant and positive effect on cloud computing adoption, which supports hypotheses $\mathrm{H} 1-\mathrm{H} 7$. The results show that all the dimensions of cloud service capability significantly affect the adoption of cloud computing. Detailed conclusions for each hypothesis are shown in Table 8.

It is also worth noting that, among the control variables, cloud computing vendor size $(\beta=1.244, p<0.001)$ has significant and positive influence on cloud computing adoption, which means that users are more willing to adopt cloud computing when the vendors are larger; and the types of vendors also have significant and positive influence on cloud computing adoption $(\beta=0.089, p<0.05)$. These are in line with common understanding that the size and types of vendors can impact their customers to adopt their products.

\section{Discussion}

The research question of this study is how the cloud computing vendors affect the adoption of cloud computing. This paper constructed the conceptualization of cloud service capability, developed scale to measure it, and empirically tested the relationships between it and adoption of cloud computing. Cloud service capability was defined as cloud computing vendor's ability to meet the needs of enterprises migrating to cloud, including 7 dimensions which are technical, security, marketing, consulting, platform, customer expertise, and responsiveness. The statistical analysis shows that all of the dimensions of cloud service capability significantly affect the adoption of cloud computing.

Technical capability of the vendors defines the traits of their offerings. Vendors with strong technical capability can develop cloud computing offerings that are more technologically advanced and easier to use which can enhance user' perceived ease of use and perceived usefulness. These factors had been proved to increase the adoption of cloud computing.

For security capability, concerns about the security and privacy of cloud computing are important factors that deter enterprises from migrating to the cloud. Vendors with stronger security capability can improve the security of the data stored by customers in the cloud and reduce the likelihood of data leakage, thus promoting the adoption of cloud computing.

For customer domain knowledge capability, having stronger capability in this regard can better meet the unique needs of customers, offer more services relevant to their business [113], and enhance their performance expectations [83], thereby increasing cloud computing adoption.

Stronger marketing capability makes customers better informed of cloud services through market education and reducing the lack of awareness of cloud services [33]. It also enables businesses to discover the benefits of cloud computing without a trial [10], thus enhancing its adoption.

Making consulting available to customers can enable cloud implementation to be supported by the organization's top management [114], eliminate customer business concerns [80], and improve customer IT management structures and processes [47], thus enhancing the adoption of these services.

Platform capability refers to the ability of a cloud service provider to integrate supply-side resources to provide a "package" solution to its customers. Cloud service providers with greater platform capability can reduce the complexity of cloud services, increase their compatibility [68], and reduce uncertainty in cloud service implementation [93], thereby increasing adoption. 
TABle 5: The GoF of the model.

\begin{tabular}{|c|c|c|c|c|c|}
\hline Model & $\chi^{2 / \mathrm{df}}$ & CFI & TLI & RMSEA & SRMR \\
\hline $\begin{array}{l}\text { Seven-factor: } \\
\text { TECC, SECC, CDKC, MARC, CONC, PLAC, RESP }\end{array}$ & 1.713 & 0.972 & 0.958 & 0.088 & 0.057 \\
\hline $\begin{array}{l}\text { Six-factor: } \\
\text { TECC, SECC, CDKC, MARC, CONC, PLAC + RESP }\end{array}$ & 2.479 & 0.894 & 0.897 & 0.124 & 0.078 \\
\hline $\begin{array}{l}\text { Five-factor: } \\
\text { TECC, SECC, CDKC, MARC, CONC + PLAC + RESP }\end{array}$ & 3.251 & 0.883 & 0.868 & 0.156 & 0.098 \\
\hline $\begin{array}{l}\text { Four-factor: } \\
\text { TECC, SECC, CDKC, MARC + CONC + PLAC + RESP }\end{array}$ & 3.892 & 0.871 & 0.798 & 0.203 & 0.102 \\
\hline $\begin{array}{l}\text { Three-factor: } \\
\text { TECC, SECC, CDKC + MARC + CONC + PLAC + RESP }\end{array}$ & 4.689 & 0.736 & 0.714 & 0.236 & 0.113 \\
\hline $\begin{array}{l}\text { Two-factor: } \\
\text { TECC, SECC + CDKC + MARC + CONC + PLAC + RESP }\end{array}$ & 6.892 & 0.691 & 0.667 & 0.244 & 0.121 \\
\hline $\begin{array}{l}\text { One-factor: } \\
\text { TECC + SECC + CDKC + MARC + CONC + PLAC + RESP }\end{array}$ & 8.560 & 0.667 & 0.556 & 0.287 & 0.126 \\
\hline
\end{tabular}

+ means fusion; CFI: comparative fit index; TLI: Tucker-Lewis index; RMSEA: root mean square error of approximation; SRMR: standardized root mean square residual; TECC: technical capability; SECC: security capability; CDKC: customer domain knowledge capability; MARC: marketing capability; CONC: consulting capability; PLAC: platform capability; RESP: responsiveness.

TABLE 6: Results of confirmatory factor analysis.

\begin{tabular}{|c|c|c|c|c|c|}
\hline Constructs & Items & Loading & AVE & $\alpha$ & CR \\
\hline \multirow{2}{*}{ Cloud computing adoption (ADOP) } & ADOP1 & 0.762 & \multirow{2}{*}{0.558} & \multirow{2}{*}{0.845} & \multirow{2}{*}{0.716} \\
\hline & ADOP2 & 0.731 & & & \\
\hline \multirow{5}{*}{ Technical capability (TECC) } & TECC1 & 0.721 & \multirow{5}{*}{0.561} & \multirow{5}{*}{0.812} & \multirow{5}{*}{0.864} \\
\hline & TECC2 & 0.624 & & & \\
\hline & TECC3 & 0.759 & & & \\
\hline & TECC4 & 0.803 & & & \\
\hline & TECC5 & 0.821 & & & \\
\hline \multirow{4}{*}{ Security capability (SECC) } & SECC1 & 0.853 & \multirow{4}{*}{0.646} & \multirow{4}{*}{0.893} & \multirow{4}{*}{0.879} \\
\hline & SECC2 & 0.796 & & & \\
\hline & SECC3 & 0.835 & & & \\
\hline & SECC4 & 0.725 & & & \\
\hline \multirow{4}{*}{ Customer domain knowledge capability (CDKC) } & CDKC1 & 0.759 & \multirow{4}{*}{0.659} & \multirow{4}{*}{0.875} & \multirow{4}{*}{0.885} \\
\hline & CDKC2 & 0.887 & & & \\
\hline & CDKC3 & 0.792 & & & \\
\hline & CDKC4 & 0.804 & & & \\
\hline \multirow{5}{*}{ Marketing capability (MARC) } & MARC1 & 0.726 & \multirow{5}{*}{0.598} & \multirow{5}{*}{0.807} & \multirow{5}{*}{0.881} \\
\hline & MARC2 & 0.785 & & & \\
\hline & MARC3 & 0.812 & & & \\
\hline & MARC4 & 0.698 & & & \\
\hline & MARC5 & 0.836 & & & \\
\hline \multirow{6}{*}{ Consulting capability (CONC) } & CONC1 & 0.698 & \multirow{6}{*}{0.613} & \multirow{6}{*}{0.872} & \multirow{6}{*}{0.904} \\
\hline & CONC2 & 0.769 & & & \\
\hline & CONC3 & 0.832 & & & \\
\hline & CONC4 & 0.846 & & & \\
\hline & CONC5 & 0.697 & & & \\
\hline & CONC6 & 0.839 & & & \\
\hline \multirow{6}{*}{ Platform capability (PLAC) } & PLAC1 & 0.722 & \multirow{7}{*}{0.609} & \multirow{6}{*}{0.893} & \multirow{7}{*}{0.903} \\
\hline & PLAC2 & 0.773 & & & \\
\hline & PLAC3 & 0.824 & & & \\
\hline & PLAC4 & 0.818 & & & \\
\hline & PLAC5 & 0.687 & & & \\
\hline & PLAC6 & 0.845 & & & \\
\hline & RESP1 & 0.736 & & & \\
\hline Responsiveness (RESP) & RESP2 & 0.755 & 0.586 & 0.905 & 0.809 \\
\hline & RESP3 & 0.803 & & & \\
\hline
\end{tabular}


TABLE 7: Correlation coefficient matrix.

\begin{tabular}{|c|c|c|c|c|c|c|c|c|}
\hline & ADOP & TECC & SECC & CDKC & MARC & CONC & PLAC & RESP \\
\hline ADOP & 0.75 & & & & & & & \\
\hline TECC & $0.06_{*}$ & 0.75 & & & & & & \\
\hline SECC & $0.35_{* *}^{*}$ & $0.40_{* * *}$ & 0.80 & & & & & \\
\hline CDKC & $0.29_{* * *}$ & $0.49_{* * *}$ & $0.49_{* *}$ & 0.81 & & & & \\
\hline MARC & $0.03_{* * *}$ & $0.41_{* *}$ & $0.09_{* *}$ & $0.60_{* *}$ & 0.77 & & & \\
\hline CONC & $0.36_{* * *}$ & $0.25_{* *}$ & $0.06_{*}$ & $0.40_{* * *}$ & $0.55_{* * *}$ & 0.78 & & \\
\hline PLAC & $0.47_{* * *}$ & $0.23_{* *}^{* *}$ & $0.12_{* *}^{*}$ & $0.32_{* *}$ & $0.46_{* * *}$ & $0.45_{* *}$ & 0.78 & \\
\hline RESP & $0.15_{*}$ & $0.04_{* *}$ & $0.02_{*}$ & $0.02_{*}^{*}$ & $0.03_{* *}$ & $0.02_{*}$ & 0.00 & 0.77 \\
\hline MEAN & 5.82 & 5.02 & 5.36 & 5.96 & 5.32 & 5.15 & 5.46 & 5.23 \\
\hline S.D. & 1.02 & 1.32 & 1.36 & 0.96 & 0.85 & 1.12 & 0.65 & 0.96 \\
\hline MIN & 1 & 1 & 1 & 1 & 1 & 1 & 1 & 1 \\
\hline MAX & 7 & 7 & 7 & 7 & 7 & 7 & 7 & 7 \\
\hline
\end{tabular}

Notes: ${ }^{*} p<0.01 ;{ }^{* *} p<0.01 ;{ }^{* *} p<0.001$. The diagonal bold numbers are the square roots of factors' AVE.

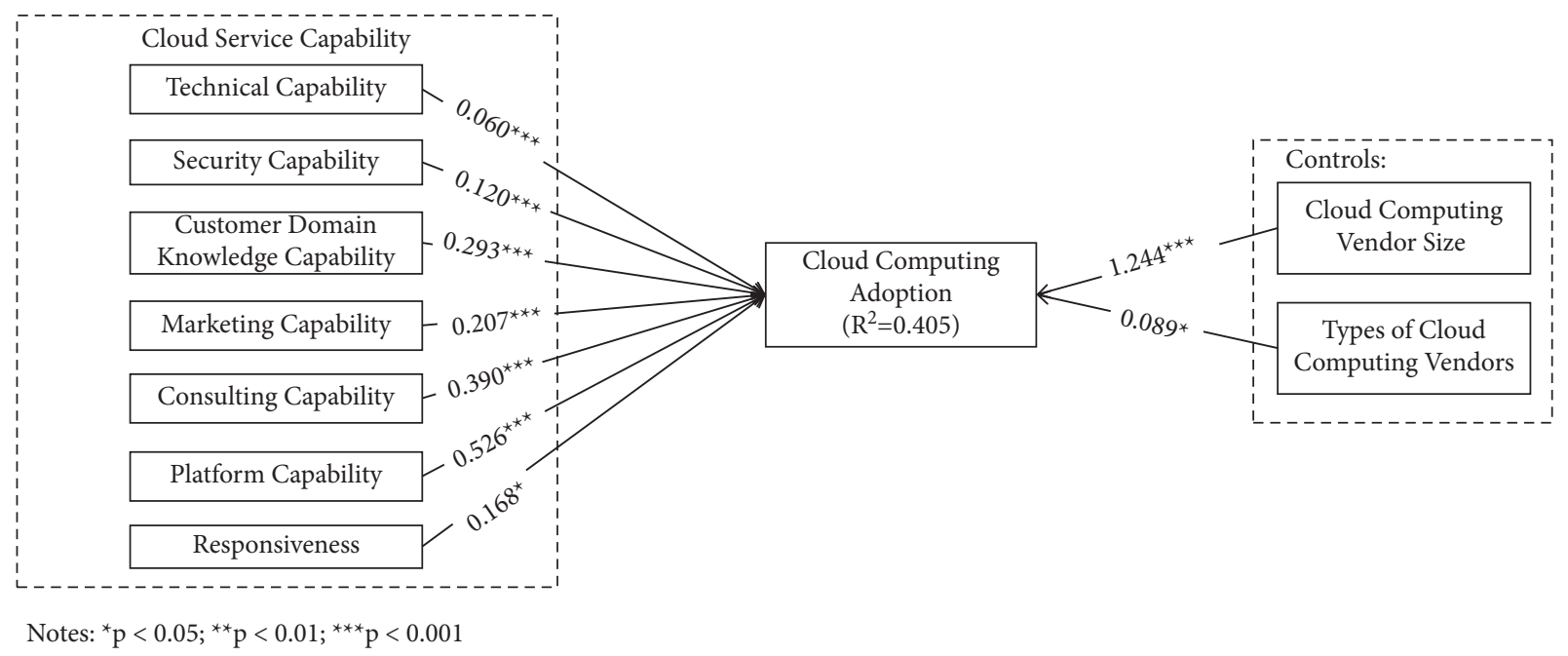

Figure 3: Results of hypothesis testing.

TABLE 8: Conclusions of hypothesis testing.

\begin{tabular}{lcccc}
\hline & & Hypotheses & $\beta$ & $p$ \\
\hline H1 & Technical capability positively influences the adoption of cloud computing. & 0.060 & $<0.001$ & Supported \\
H2 & Security capability positively influences the adoption of cloud computing. & 0.120 & $<0.001$ & Supported \\
H3 & Customer domain knowledge capability positively influences the adoption of cloud computing. & 0.293 & $<0.001$ & Supported \\
H4 & Marketing capability positively influences the adoption of cloud computing. & 0.207 & $<0.001$ & Supported \\
H5 & Consulting capability positively influences the adoption of cloud computing. & 0.390 & $<0.001$ & Supported \\
H6 & Platform capability positively influences the adoption of cloud computing. & 0.526 & $<0.001$ & Supported \\
H7 & Responsiveness positively influences the adoption of cloud computing. & 0.168 & $<0.05$ & Supported \\
\hline
\end{tabular}

The use of cloud computing is a continuous process, and if failures occur and are not resolved, this will reduce the stability of customers' operation. However, greater responsiveness will enhance stability [94], security, and trust [46] of the cloud computing, thus enhancing the adoption of cloud services.

Similar concepts had been raised in previous research, such as the work of Carroll, Helfert, and Lynn [23], which defined cloud service capability and developed an assessment framework. However, Carroll et al.'s study, on one hand, assessed cloud service capability from the perspective of the adopters. On the other hand, the cloud computing was in infancy so that a lot of characteristics had been neglected in that study. This paper's results are more objective and direct for the data are from the vendors, and the dimensions of cloud service capability such as platform capability and consulting capability are new advance in cloud computing, making the findings more precise. 
TABLE 9:

\begin{tabular}{|c|c|}
\hline \# & Measurement Item \\
\hline & Demographic information: filled by vendors \\
\hline 1 & What's type of service your firm offers? IaaS; PaaS; SaaS; hybrid. \\
\hline 2 & How many employees does your firm employ? \\
\hline & $\begin{array}{c}\text { Cloud service capability (developed by ourselves): filled by vendors } \\
\text { From } 1 \text { (strongly disagree) to } 7 \text { (strongly agree). } \\
\text { (1) Technical capability }\end{array}$ \\
\hline TECC1 & We are very capable of developing cloud computing. \\
\hline TECC2 & We are constantly updating our technology. \\
\hline TECC3 & Our products are highly scalable. \\
\hline TECC4 & Our products have very high performance. \\
\hline TECC5 & Our products are highly flexible. \\
\hline & (2) Security capability \\
\hline SECC1 & We do not snoop on our customers' data. \\
\hline SECC2 & We do not steal our customers' data. \\
\hline SECC3 & We invest in security technology. \\
\hline SECC4 & Data security is our main concern. \\
\hline
\end{tabular}

SECC4

(3) Customer domain knowledge capability

We know our clients' industries.

CDKC1

$\mathrm{CDKC} 3$

We are familiar with the business in which our clients are involved.

CDKC4

We adapt the cloud implementation process to the customer's requirements.

We will adapt the cloud architecture to the customer's requirements.

$\begin{array}{lc}\text { MARC1 } & \text { (4) Marketing capability } \\ \text { MARC2 } & \text { Our prices are very advantageous. } \\ \text { MARC3 } & \text { We offer our customers a discount on ongoing use. } \\ \text { MARC4 } & \text { We will show our customers the benefits of cloud computing. } \\ \text { MARC5 } & \text { We show our customers what we have to offer. }\end{array}$

\begin{tabular}{lc}
\hline & (5) Consulting capability \\
CONC1 & We help CIOs convince CEOs of the importance of cloud computing. \\
CONC2 & We will advise on client management. \\
CONC3 & We help companies plan and optimize their business processes with cloud computing. \\
CONC4 & We help companies transform their business models with cloud computing. \\
CONC5 & We help companies leverage the cloud for digital transformation. \\
CONC6 & We help our clients integrate their upstream and downstream businesses.
\end{tabular}

(6) Platform capability

PLAC1

PLAC2

PLAC3

PLAC4

PLAC5

PLAC6

RESP1

RESP2

RESP3
We do not lock our customers into the cloud services we offer.

There is compatibility between my cloud computing product and other companies' cloud computing products. We offer complete cloud computing solutions.

We integrate infrastructure providers.

We integrate SaaS providers.

We have integrated PaaS providers.

\section{(7) Responsiveness}

Customer cloud services are running very stably.

We can be alerted immediately to problems in the operation of customer clouds.

We can respond immediately to problems in customer cloud operations.

Cloud computing adoption (adapted from Oliveira, Thomas, and Espadanal [52]): filled by customers corresponding to the vendors From 1 (strongly disagree) to 7 (strongly agree).

Our organization is currently engaged in cloud computing.

ADOP1

ADOP2

We are anticipating that our company will adopt cloud computing in the future.

\section{Conclusions}

Extant research mainly studied the factors which influence the adoption of cloud computing from the adopter side, while its delivery model and scalability characteristics make the role of its vendor service capabilities more important. Therefore, this study shifts the research perspective from the adopter to the supplier. This study conceptualized the construct of cloud service capability and developed the scale of it by qualitative research and identified seven dimensions of cloud service capability. After the pretest, the formal scale to measure cloud service capability was obtained. Then, this research empirically tested the influence of these capabilities on cloud computing adoption, and the results showed that all 7 capabilities can promote cloud computing adoption. The rest below depicts the implications of this work and gives the future research directions. 
6.1. Implications for Research. The main contributions of this study are constructing the conceptualization of cloud service capability and empirically testing its impact on cloud computing adoption.

Firstly, previous studies on the adoption of cloud computing have been mainly conducted from the perspective of the adopters, with the characteristics of cloud computing as perceived by the adopters as the independent variables. However, such a research perspective has some shortcomings: it lacks objectivity and fails to consider the influence of cloud computing vendors on the adoption of cloud computing. Therefore, this paper studies the adoption of cloud computing from the perspective of cloud computing vendors. Most of the characteristics of cloud computing perceived by the adopters are, to some extent, determined by the vendors' cloud service capability. For example, some studies suggest that cloud computing adoption is affected by perceived stability [15], but, in fact, it is the responsiveness of the vendor that is the key determinant of stability. Cloud computing product is more stable if its vendor is able to respond to and resolve faults that occur during its usage in a timely manner. Similarly, perceived usefulness and ease of use are also related to the vendors' cloud service capability. Vendors with greater customer expertise can develop cloud computing products that better meet the requirements of adopters. This increases the ease of use and usefulness of cloud computing, and other dimensions of cloud service capability play in similar ways.

Secondly, extant research on cloud computing adoption has viewed cloud computing as products, thus studying the factor impacting the adoption from a product perspective. However, cloud computing offerings differ from the software products such as ERP and DSS which are relatively stable in operation, single in function, and independent of other software products. Its definition and its mode of delivery make cloud computing be more service-oriented in essence. Therefore, this study shifts into the service perspective to examine how cloud computing vendors meet customers' needs by offering services which usually are not the primary parts of traditional software industry; and, through developing the definition of cloud service capability, our study detected what services influence the adoption of cloud computing, which offer scholars more neoteric and comprehensive insights to research its adoption. For example, cloud computing vendors should develop customer domain knowledge capability to satisfy the customized requirement and platform capability to offer package solution to lighten the burden of the customers to search for appropriate mashup. All of these accelerate the adoption of cloud computing.

6.2. Implications for Practice. Firstly, this study can offer insights for the cloud computing vendors to build cloud service capability. There are cloud computing vendors which are transformed from traditional information technology companies, such as Microsoft Azure and Amazon Web Services. Vendors transformed from traditional information technology companies usually have strong IT capability.
However, according to our research results, other capabilities also play an important role in cloud computing adoption. Thus, the vendors should build cloud service capability to obtain potential customers and provide better services. Cloud service capability and its dimensions constructed in this study can guide these companies in developing their service capability after transitioning to cloud computing vendors.

Secondly, this study can offer suggestions for enterprises which intend to migrate to cloud to select the most appropriate vendors. The dimensions and items of the scale of cloud computing capability can be reference for enterprises when selecting a cloud service vendor. For example, if enterprises need to involve multiple types of cloud services such as IaaS and SaaS in the process of migrating to cloud, they can choose the vendor with strong platform capability. Enterprises with high requirements for data security can focus on the security capability of the cloud computing vendor. Enterprises with high requirements for system stability can pay attention to the technical capability and responsiveness of the vendors to improve stability and ensure that the system can be handled in a timely manner in case of failure.

6.3. Limitations and Future Research Directions. This study is subject to limitations, which may also suggest future research opportunities. Firstly, this paper measured all of the constructs based on self-reporting data, and we were not able to obtain any objective measures to supplement our data set. The survey methodology as this study adopted also prevents us from investigating into the detailed underlying mechanisms through which our findings emerge. Future studies may extend this research or corroborate the findings by leveraging archival data sets or in-depth case studies.

Secondly, this research only considered the factors influence on the adoption of cloud computing from the vendors and assumed that the factors of the vendors play the role through impacting the users. However, the survey methodology prevents this paper from investigating into the detailed underlying mechanisms.

Thirdly, although (1) many nationwide cloud computing vendors set up branches and subsidiaries in Shandong and vendors registered in Shandong provide cloud computing nationwide, (2) Shandong Province's economy is wellknown for its comprehensiveness of industrial system, and (3) Government-supported study offered the opportunity to collect vendor-adopter paired data and levelled up the representativeness of the data. However, it must be acknowledged that data from a single province is one of limitations of this study. In the future, we will look for more random ways to collect data to validate the generalizability of the results.

Fourthly, this research only tested the influence of the cloud service capability on the adoption of cloud computing, ignoring its other impacts such as the value cocreated between the vendors and the customers. In the future, other influences of cloud service capability will be tested (Table 9). 


\section{Data Availability}

The data used to support the findings of this study are available from the corresponding author upon request.

\section{Conflicts of Interest}

The authors declare that there are no conflicts of interest regarding the publication of this paper.

\section{Acknowledgments}

This work was supported by the Soft Science Project of Shandong Province (Grant no. 2021RKY03046) and the Shandong Province Higher Educational Science and Technology Program of China (Grant no. J17KA066).

\section{References}

[1] R. Buyya, C. S. Yeo, and S. Venugopal, "Market-oriented cloud computing: vision, hype, and reality for delivering it services as computing utilities," in Proceedings of the 2008 10th IEEE International Conference on High Performance Computing and Communications, pp. 5-13, Dalian, China, September 2008.

[2] P. K. Senyo, J. Effah, and E. Addae, "Preliminary insight into cloud computing adoption in a developing country," Journal of Enterprise Information Management, vol. 29, no. 4, pp. 505-524, 2016.

[3] P. K. Senyo, E. Addae, and R. Boateng, "Cloud computing research: a review of research themes, frameworks, methods and future research directions," International Journal of Information Management, vol. 38, no. 1, pp. 128-139, 2018.

[4] W. Venters and E. A. Whitley, "A critical review of cloud computing: researching desires and realities," Journal of Information Technology, vol. 27, no. 3, pp. 179-197, 2012.

[5] H. Yang and M. Tate, "A descriptive literature review and classification of cloud computing research," Communications of the Association for Information Systems, vol. 31, no. 1, p. 2, 2012.

[6] D.-W. Sun, G.-R. Chang, S. Gao, L.-Z. Jin, and X.-W. Wang, "Modeling a dynamic data replication strategy to increase system availability in cloud computing environments," Journal of Computer Science and Technology, vol. 27, no. 2, pp. 256-272, 2012.

[7] R. Yu, C. Wu, B. Yan et al., "Analysis of the impact of big data on E-commerce in cloud computing environment," Complexity, vol. 2021, no. 2, 12 pages, Article ID 5613599, 2021.

[8] A. K. Bardsiri and S. M. Hashemi, "Qos metrics for cloud computing services evaluation," International Journal of Intelligent Systems and Applications, vol. 6, no. 12, pp. 27-33, 2014.

[9] S. Slimani, T. Hamrouni, and F. Ben Charrada, "Serviceoriented replication strategies for improving quality-ofservice in cloud computing: a survey," Cluster Computing, vol. 24, no. 1, pp. 361-392, 2021.

[10] Y. Alshamaila, S. Papagiannidis, and F. Li, "Cloud computing adoption by SMEs in the north east of England," Journal of Enterprise Information Management, vol. 26, no. 3, pp. 250-275, 2013.

[11] C.-R. Choi and Y.-J. Song, "Relative weight decision of qualiy attributes in cloud computing service using ANP,"
International Journal of Advancements in Computing Technology, vol. 4, no. 5, pp. 240-248, 2012.

[12] Q. She, X. Wei, G. Nie, and D. Chen, "QoS-aware cloud service composition: a systematic mapping study from the perspective of computational intelligence," Expert Systems with Applications, vol. 138, p. 112804, 2019.

[13] S. L. Jarvenpaa and J.-Y. Mao, "Operational capabilities development in mediated offshore software services models," Journal of Information Technology, vol. 23, no. 1, pp. 3-17, 2008.

[14] F. Li, M. Vögler, and M. Claeßens, "Efficient and scalable IoT service delivery on cloud," in Proceedings of the 2013 IEEE Sixth International Conference on Cloud Computing, pp. 740-747, Santa Clara, CA, USA, July 2013.

[15] H. Shen and G. Liu, "An efficient and trustworthy resource sharing platform for collaborative cloud computing," IEEE Transactions on Parallel and Distributed Systems, vol. 25, no. 4, pp. 862-875, 2013.

[16] M. B. Ali, "Multi-perspectives of cloud computing service adoption quality and risks in higher education," in Handbook of Research on Modern Educational Technologies, Applications, and ManagementIGI Global, Hershey, PA, USA, 2021.

[17] S. M. Habib, S. Ries, and M. Muhlhauser, "Cloud computing landscape and research challenges regarding trust and reputation," in Proceedings of the 2010 7th International Conference on Ubiquitous Intelligence \& Computing and 7th International Conference on Autonomic \& Trusted Computing, pp. 410-415, Xi'an, China, October 2010.

[18] A. Comi, L. Fotia, and F. Messina, "A reputation-based approach to improve qos in cloud service composition," in Proceedings of the 2015 IEEE 24th International Conference on Enabling Technologies: Infrastructure for Collaborative Enterprises, pp. 108-113, Larnaca, Cyprus, June 2015.

[19] A. Köster, C. Matt, and T. Hess, "Carefully choose your (payment) partner: how payment provider reputation influences m-commerce transactions," Electronic Commerce Research and Applications, vol. 15, pp. 26-37, 2016.

[20] N. Alkhater, R. Walters, and G. Wills, "An empirical study of factors influencing cloud adoption among private sector organisations," Telematics and Informatics, vol. 35, no. 1, pp. 38-54, 2018.

[21] A. Khayer, M. S. Talukder, Y. Bao, and M. N. Hossain, "Cloud computing adoption and its impact on SMEs' performance for cloud supported operations: a dual-stage analytical approach," Technology in Society, vol. 60, p. 101225, 2020.

[22] O. Avila, C. Paez, and D. Correal, "Towards a maturity model for cloud service customizing," in Proceedings of the International Conference on Applied Informatics, pp. 282-294, Madrid, Spain, November 2019.

[23] N. Carroll, M. Helfert, and T. Lynn, "Towards the development of a cloud service capability assessment framework," in Continued Rise of the CloudSpringer, London, UK, 2014.

[24] A. Vakili and N. J. Navimipour, "Comprehensive and systematic review of the service composition mechanisms in the cloud environments," Journal of Network and Computer Applications, vol. 81, pp. 24-36, 2017.

[25] P. Priyadarshinee, R. D. Raut, M. K. Jha, and B. B. Gardas, "Understanding and predicting the determinants of cloud computing adoption: a two staged hybrid SEM - neural Networks Approach," Computers in Human Behavior, vol. 76, no. 1, pp. 341-362, 2017. 
[26] Y. Jadeja and K. Modi, "Cloud computing-concepts, architecture and challenges," in Proceedings of the 2012 International Conference on Computing, Electronics and Electrical Technologies (ICCEET), pp. 877-880, Kanyakumari, India, March 2012.

[27] A. Azarnik, J. Shayan, and M. Alizadeh, "Associated risks of cloud computing for SMEs," Open International Journal of Informatics, vol. 1, no. 1, pp. 37-45, 2012.

[28] A. Dutta, G. C. A. Peng, and A. Choudhary, "Risks in enterprise cloud computing: the perspective of IT experts," Journal of Computer Information Systems, vol. 53, no. 4, pp. 39-48, 2013.

[29] S. Marston, Z. Li, S. Bandyopadhyay, J. Zhang, and A. Ghalsasi, "Cloud computing - the business perspective," Decision Support Systems, vol. 51, no. 1, pp. 176-189, 2011.

[30] S. M. Salleh, S. Y. Teoh, and C. Chan, Cloud Enterprise Systems: A Review of Literature and its AdoptionPACIS, Nakuru, Kenya, 2012.

[31] A. Aleem and C. R. Sprott, "Let me in the cloud: analysis of the benefit and risk assessment of cloud platform," Journal of Financial Crime, vol. 20, no. 1, pp. 6-24, 2013.

[32] M. Armbrust, A. Fox, R. Griffith et al., "A view of cloud computing," Communications of the ACM, vol. 53, no. 4, pp. 50-58, 2010.

[33] M. Z. Nkhoma, D. Dang, and A. De Souza-Daw, "Contributing factors of cloud computing adoption: a technologyorganisation-environment framework approach," in Proceedings of the European Conference on Information Management \& Evaluation, pp. 180-188, Sopot, Poland, September 2013.

[34] M. Abdel-Basset, M. Mohamed, and V. Chang, "NMCDA: a framework for evaluating cloud computing services," Future Generation Computer Systems, vol. 86, pp. 12-29, 2018.

[35] O. Al-Hujran, E. M. Al-Lozi, M. M. Al-Debei, and M. Maqableh, "Challenges of cloud computing adoption from the TOE framework perspective," International Journal of E-Business Research, vol. 14, no. 3, pp. 77-94, 2018.

[36] M. Shuaib, A. Samad, S. Alam, and S. T. Siddiqui, "Why adopting cloud is still a challenge?-A review on issues and challenges for cloud migration in organizations," Advances in Intelligent Systems and Computing, vol. 904, pp. 387-399, 2019.

[37] E. Loukis, M. Janssen, and I. Mintchev, "Determinants of software-as-a-service benefits and impact on firm performance," Decision Support Systems, vol. 117, pp. 38-47, 2019.

[38] P. R. Palos-Sanchez, F. J. Arenas-Marquez, and M. AguayoCamacho, "Cloud computing (SaaS) adoption as a strategic technology: results of an empirical study," Mobile Information Systems, vol. 2017, no. 3, pp. 1-20, 2017.

[39] G. Zhang, Y. Chen, and G. Li, "The evolution and emerging trends of cloud computing adoption research: visual analysis of CiteSpace based on WOS papers," in Proceedings of the 2020 3rd International Conference on Signal Processing and Machine Learning, pp. 40-47, Beijing, China, October 2020.

[40] O. M. Yigitbasioglu, "The role of institutional pressures and top management support in the intention to adopt cloud computing solutions," Journal of Enterprise Information Management, vol. 28, no. 4, pp. 579-594, 2015.

[41] M. Stieninger, D. Nedbal, and W. Wetzlinger, "Factors influencing the organizational adoption of cloud computing: a survey among cloud workers," International Journal of Information Systems and Project Management, vol. 6, no. 1, pp. 5-23, 2018.
[42] M. Espadanal and T. Oliveira, "Cloud computing adoption by firms," MCIS, vol. 30, 2012.

[43] H. Takabi, J. B. D. Joshi, and G.-J. Ahn, "Security and privacy in cloud computing," in Principles, Methodologies, and Service-Oriented Approaches for Cloud ComputingIGI Global, Hershey, PA, USA, 2013.

[44] Z. Xiao and Y. Xiao, "Security and privacy in cloud computing," IEEE communications surveys \& tutorials, vol. 15, no. 2, pp. 843-859, 2012.

[45] R. El-Gazzar, E. Hustad, and D. H. Olsen, "Understanding cloud computing adoption issues: a Delphi study approach," Journal of Systems and Software, vol. 118, pp. 64-84, 2016.

[46] W.-W. Wu, "Mining significant factors affecting the adoption of SaaS using the rough set approach," Journal of Systems and Software, vol. 84, no. 3, pp. 435-441, 2011.

[47] H. P. Borgman, B. Bahli, and H. Heier, "Cloudrise: exploring cloud computing adoption and governance with the TOE framework," in Proceedings of the 2013 46th Hawaii International Conference on System Sciences, pp. 4425-4435, Maui, HI, USA, January 2013.

[48] H. F. Naqvi, F. H. Chandio, and A. F. Soomro, "Software as a service acceptance model: a user-centric perspective in cloud computing context," in Proceedings of the 2018 IEEE 5th International Conference on Engineering Technologies and Applied Sciences (ICETAS), pp. 1-4, Bangkok, Thailand, November 2018.

[49] S. K. Sharma, A. H. Al-Badi, S. M. Govindaluri, and M. H. AlKharusi, "Predicting motivators of cloud computing adoption: a developing country perspective," Computers in $\mathrm{Hu}$ man Behavior, vol. 62, pp. 61-69, 2016.

[50] A. Bhattacherjee and S. C. Park, "Why end-users move to the cloud: a migration-theoretic analysis," European Journal of Information Systems, vol. 23, no. 3, pp. 357-372, 2014.

[51] H. Gangwar, H. Date, and R. Ramaswamy, "Understanding determinants of cloud computing adoption using an integrated TAM-TOE model," Journal of Enterprise Information Management, vol. 26, no. 3, pp. 250-275, 2015.

[52] T. Oliveira, M. Thomas, and M. Espadanal, "Assessing the determinants of cloud computing adoption: an analysis of the manufacturing and services sectors," Information \& Management, vol. 51, no. 5, pp. 497-510, 2014.

[53] J. Baker, "The technology-organization-environment framework," Information systems theory, vol. 2012, pp. 231-245, 2012.

[54] N. Pawar, S. C. Misra, and S. Singh, "Assessment of success factors for cloud adoption in semiconductor industry using hybrid DEMATEL-ANP," in Proceedings of the 2020 IEEE International Conference on Engineering, Technology and Innovation (ICE/ITMC), pp. 1-7, Cardiff, UK, June 2020.

[55] T. Boillat and C. Legner, "From on-premise software to cloud services: the impact of cloud computing on enterprise software vendors' business models," Journal of theoretical and applied electronic commerce research, vol. 8, no. 3, pp. 39-58, 2013.

[56] L. Youseff, M. Butrico, and D. Da Silva, "Toward a unified ontology of cloud computing," in Proceedings of the 2008 Grid Computing Environments Workshop, pp. 1-10, Austin, TX, USA, November 2008

[57] M. A. Cusumano, "The changing software business: moving from products to services," Computer, vol. 41, no. 1, pp. 20-27, 2008.

[58] Q. Zhang, L. Cheng, and R. Boutaba, "Cloud computing: state-of-the-art and research challenges," Journal of internet services and applications, vol. 1, no. 1, pp. 7-18, 2010. 
[59] H. Tout, A. Mourad, C. Talhi, and H. Otrok, "AOMD approach for context-adaptable and conflict-free Web services composition," Computers \& Electrical Engineering, vol. 44, pp. 200-217, 2015.

[60] M. Al-Roomi, S. Al-Ebrahim, S. Buqrais, and I. Ahmad, "Cloud computing pricing models: a survey," International Journal of Grid and Distributed Computing, vol. 6, no. 5, pp. 93-106, 2013.

[61] S. Subashini and V. Kavitha, "A survey on security issues in service delivery models of cloud computing," Journal of Network and Computer Applications, vol. 34, no. 1, pp. 1-11, 2011.

[62] G. Peters and J. Seruga, "Network effects in the ERP systems market: an analysis of the implications of business intelligence and cloud computing," International Journal of Advanced Science and Technology, vol. 43, pp. 105-114, 2012.

[63] S. B. MacKenzie, P. M. Podsakoff, and N. P. Podsakoff, "Construct measurement and validation procedures in MIS and behavioral research: integrating new and existing techniques," MIS Quarterly, vol. 35, no. 2, pp. 293-334, 2011.

[64] J. A. Holton, "The coding process and its challenges," The Sage handbook of grounded theory, vol. 3, pp. 265-289, 2007.

[65] A. Moghaddam, "Coding issues in grounded theory," Issues in Educational Research, vol. 16, no. 1, pp. 52-66, 2006.

[66] D. V. Cicchetti, "Assessing inter-rater reliability for rating scales: resolving some basic issues," British Journal of Psychiatry, vol. 129, no. 5, pp. 452-456, 1976.

[67] H. Hoehle, V. Venkatesh, and V. Venkatesh, "Mobile application usability: conceptualization and instrument development," MIS Quarterly, vol. 39, no. 2, pp. 435-472, 2015.

[68] C. Low, Y. Chen, and M. Wu, "Understanding the determinants of cloud computing adoption," Industrial Management \& Data Systems, vol. 111, no. 7, pp. 1006-1023, 2011.

[69] H. Pan, Y. Yuan, and W. Song, "The design and implementation of secure cloud desktop system," in Proceedings of the International Conference on Signal and Information Processing, Networking and Computers, pp. 212-218, Qingdao, China, April 2018.

[70] T. Alsafi and I.-S. Fan, "Investigation of cloud computing barriers: a case study in Saudi arabian SMEs," Journal of Information Systems Engineering and Management, vol. 5, no. 4, p. em0129, 2020.

[71] R. Lu, Y. Rahulamathavan, H. Zhu, C. Xu, and M. Wang, "Security and privacy challenges in vehicular cloud computing," Mobile Information Systems, vol. 2016, pp. 1-2, 2016.

[72] K. Popović and Ž. Hocenski, "Cloud computing security issues and challenges," in Proceedings of the 33rd International Convention Mipro, pp. 344-349, Croatia, May 2010.

[73] V. Chang, Y.-H. Kuo, and M. Ramachandran, "Cloud computing adoption framework: a security framework for business clouds," Future Generation Computer Systems, vol. 57, pp. 24-41, 2016.

[74] N. Khan and A. Al-Yasiri, "Identifying cloud security threats to strengthen cloud computing adoption framework," Procedia Computer Science, vol. 94, pp. 485-490, 2016.

[75] W. Scott, "Cloud security: is it really an issue for SMBs?" Computer Fraud \& Security, vol. 2010, no. 10, pp. 14-15, 2010.

[76] S. Trigueros-Preciado, D. Pérez-González, and P. SolanaGonzález, "Cloud computing in industrial SMEs: identification of the barriers to its adoption and effects of its application," Electronic Markets, vol. 23, no. 2, pp. 105-114, 2013.

[77] K. Kang, J. Hahn, and P. De, "Learning effects of domain, technology, and customer knowledge in information systems development: an empirical study," Information Systems Research, vol. 28, no. 4, pp. 797-811, 2017.

[78] C. Magelssen, F. Sanchez, and F. Damanpour, "Learning from outsourcing: the effects of outsourcing strategy on organizational efficiency," Academy of Management, Briarcliff Manor, NY, USA, 2015.

[79] J. Chatterjee, "Strategy, human capital investments, businessdomain capabilities, and performance: a study in the global software services industry," Strategic Management Journal, vol. 38, no. 3, pp. 588-608, 2017.

[80] P.-F. Hsu, S. Ray, and Y.-Y. Li-Hsieh, "Examining cloud computing adoption intention, pricing mechanism, and deployment model," International Journal of Information Management, vol. 34, no. 4, pp. 474-488, 2014.

[81] E. Park and K. J. Kim, "An integrated adoption model of mobile cloud services: exploration of key determinants and extension of technology acceptance model," Telematics and Informatics, vol. 31, no. 3, pp. 376-385, 2014

[82] S. Kaphle, S. Chaturvedi, I. Chaudhuri, R. Krishnan, and N. Lesh, "Adoption and usage of mHealth technology on quality and experience of care provided by frontline workers: observations from rural India," JMIR mHealth and uHealth, vol. 3, no. 2, p. e61, 2015.

[83] V. Ratten, "Cloud computing: a social cognitive perspective of ethics, entrepreneurship, technology marketing, computer self-efficacy and outcome expectancy on behavioural intentions," Australasian Marketing Journal, vol. 21, no. 3, pp. 137-146, 2013.

[84] J. Hurwitz, M. Kaufman, and A. Bowles, Cognitive Computing and Big Data Analytics, Wiley Online Library, Hoboken, NJ, USA, 2015.

[85] J. C. Olson, D. R. Toy, and P. A. Dover, "Do cognitive responses mediate the effects of advertising content on cognitive structure?" Journal of Consumer Research, vol. 9, no. 3, pp. 245-262, 1982.

[86] D. Dempsey and F. Kelliher, "Recurring revenue model through a cloud computing channel," in Industry Trends in Cloud ComputingSpringer, Berlin, Germany, 2018.

[87] P. Romano, L. Rodrigues, N. Carvalho, and J. Cachopo, "Cloud-TM," ACM SIGOPS-Operating Systems Review, vol. 44, no. 2, pp. 1-6, 2010.

[88] A. Nettsträter, T. Geißen, M. Witthaut, D. Ebel, and J. Schoneboom, "Logistics software systems and functions: an overview of ERP, WMS, TMS and SCM systems," in Cloud Computing for Logistics, M. Ten Hompel, J. Rehof, and O. Wolf, Eds., pp. 1-11, Springer International Publishing, Berlin, Germany, 2015.

[89] M. Sharma and R. Sehrawat, "A hybrid multi-criteria decision-making method for cloud adoption: evidence from the healthcare sector," Technology in Society, vol. 61, p. 101258, 2020.

[90] S. J. Berman, L. Kesterson-Townes, A. Marshall, and R. Srivathsa, "How cloud computing enables process and business model innovation," Strategy \& Leadership, vol. 40, no. 4, pp. 27-35, 2012.

[91] R. Williams, "The business of memes: memetic possibilities for marketing and management," Management Decision, vol. 38 , no. 4 , pp. $272-279,2000$.

[92] A. Heinzl, P. Buxmann, and O. Wendt, Theory-Guided Modeling and Empiricism in Information Systems Research, Springer Science \& Business Media, Berlin, Germany, 2011.

[93] C. G. Cegielski, L. A. Jones-Farmer, and Y. Wu, "Adoption of cloud computing technologies in supply chains: an 
organizational information processing theory approach," International Journal of Logistics Management, vol. 23, 2012.

[94] S. W. Shin, P. Porras, and V. Yegneswara, "Fresco: modular composable security services for software-defined networks," in Proceedings of the 20th Annual Network \& Distributed System Security Symposium, San Diego, CA, USA, February 2013.

[95] R. W. Brislin, "The wording and translation of research instruments," in Field Methods in Cross-Cultural ResearchSage Publications, Inc., Thousand Oaks, CA, USA, 1986.

[96] L. R. James, R. G. Demaree, and G. Wolf, "Estimating withingroup interrater reliability with and without response bias," Journal of Applied Psychology, vol. 69, no. 1, pp. 85-98, 1984.

[97] R. Chakraborty, S. Ramireddy, T. S. Raghu, and H. R. Rao, "The information assurance practices of cloud computing vendors," IT professional, vol. 12, no. 4, pp. 29-37, 2010.

[98] K. M. Khan and Q. Malluhi, "Establishing trust in cloud computing," IT professional, vol. 12, no. 5, pp. 20-27, 2010.

[99] J. S. Armstrong and T. S. Overton, "Estimating nonresponse bias in mail surveys," Journal of Marketing Research, vol. 14, no. 3, pp. 396-402, 1977.

[100] N. Podsakoff, "Common method biases in behavioral research: a critical review of the literature and recommended remedies," Journal of Applied Psychology, vol. 885, no. 879, 2003.

[101] P. A. Pavlou and O. A. El Sawy, "From IT leveraging competence to competitive advantage in turbulent environments: the case of new product development," Information Systems Research, vol. 17, no. 3, pp. 198-227, 2006.

[102] G. Dash and J. Paul, "CB-SEM vs PLS-SEM methods for research in social sciences and technology forecasting," Technological Forecasting and Social Change, vol. 173, p. 121092, 2021.

[103] X. Li, J. Du, and H. Long, "Mechanism for green development behavior and performance of industrial enterprises (GDBP-IE) using partial least squares structural equation modeling (PLS-SEM)," International Journal of Environmental Research and Public Health, vol. 17, no. 22, p. 8450, 2020.

[104] A. E. Hurley, T. A. Scandura, C. A. Schriesheim et al., "Exploratory and confirmatory factor analysis: guidelines, issues, and alternatives," Journal of Organizational Behavior, vol. 18, no. 6, pp. 667-683, 1997.

[105] B. L. Mak and H. Sockel, "A confirmatory factor analysis of IS employee motivation and retention," Information \& Management, vol. 38, no. 5, pp. 265-276, 2001.

[106] J. B. Schreiber, A. Nora, F. K. Stage, E. A. Barlow, and J. King, "Reporting structural equation modeling and confirmatory factor analysis results: a review," The Journal of Educational Research, vol. 99, no. 6, pp. 323-338, 2006.

[107] R. P. Bagozzi, "Evaluating structural equation models with unobservable variables and measurement error: a comment," Journal of Marketing Research, vol. 18, no. 3, pp. 375-381, 1981.

[108] A. Purwanto, "Partial least squares structural squation modeling (PLS-SEM) analysis for social and management research: a literature review," Journal of Industrial Engineering \& Management Research, vol. 2, no. 4, pp. 114-123, 2021.

[109] B. H. Wixom and H. J. Watson, "An empirical investigation of the factors affecting data warehousing success," MIS Quarterly, vol. 25, no. 1, pp. 17-41, 2001.
[110] W. W. Chin, B. L. Marcolin, and P. R. Newsted, "A partial least squares latent variable modeling approach for measuring interaction effects: results from a Monte Carlo simulation study and an electronic-mail emotion/adoption study," Information Systems Research, vol. 14, no. 2, pp. 189-217, 2003.

[111] M. Sarstedt, L. Radomir, O. I. Moisescu, and C. M. Ringle, "Latent class analysis in PLS-SEM: a review and recommendations for future applications," Journal of Business Research, vol. 138, pp. 398-407, 2022.

[112] C. Fornell and D. F. Larcker, "Evaluating structural equation models with unobservable variables and measurement error," Journal of Marketing Research, vol. 24, no. 2, pp. 337-346, 1981.

[113] N. Opitz, T. F. Langkau, and N. H. Schmidt, "Technology acceptance of cloud computing: empirical evidence from German IT departments," in Proceedings of the 2012 45th Hawaii International Conference on System Sciences, pp. 1593-1602, Maui, HI, USA, January 2012.

[114] R. Tjikongo and W. Uys, "The viability of cloud computing adoption in SMME's in Namibia," in Proceedings of the 2013 IST-Africa Conference \& Exhibition, pp. 1-11, Nairobi, Kenya, May 2013. 